\title{
Sobre la esencia individual
}

\author{
Pilar FERnÁndez Beites \\ Facultad de Filosofía \\ Universidad Pontificia de Salamanca \\ pfernandezbe@upsa.es
}

\begin{abstract}
Resumen: Este artículo trata el problema de la esencia individual con el apoyo de la ontología de Zubiri, en la que la individuación no se entiende sólo como la mera "singularidad" de la filosofía clásica, sino como "diversidad". La teoría zubiriana se completa introduciendo un nuevo sentido de individualidad propio del hombre: la individualidad como "irrepetibilidad". Para explicar esta individualidad fuerte se utiliza la teoría de Scheler, la cual insiste en lo irrepetible del "espíritu" humano y sostiene que la esencia individual de la persona está dada por un carácter espiritual (ethos), por un ordo amoris. Finalmente, en polémica con Scheler, se sugiere que es la libertad la que aporta la individualidad como irrepetibilidad.
\end{abstract}

Palabras clave: libertad, irrepetibilidad, Scheler, Zubiri

\begin{abstract}
This article deals with the problem of individual essence by appealing to Zubiri's ontology, in which individuation is not only understood as mere singularity, like in classical philosophy, but as "diversity". Zubiri's theory is completed by introducing a new sense of individuality proper to humankind: individuality as "unrepeatability". In order to account for this strong individuality, I use Scheler's theory, which insists on the unrepeatability of the human "spirit", and holds that the individual essence of the person depends on a spiritual character (ethos), and on an ordo amoris. Finally, in controversy with Scheler, I suggest that what provides individuality as unrepeatability is liberty.
\end{abstract}

Key words: liberty, unrepeatability, Scheler, Zubiri

¿Puede repetirse un ser humano? ¿Puede sustituirse un hombre por una copia suya, que sea exactamente igual al original, de modo que podamos afirmar con toda seriedad que nada ha cambiado?

En el mundo no humano, la repetición de individuos es, sin duda, posible. Si se me estropea el ordenador con el que trabajo a diario, lo puedo sustituir por otro igual. Quizás el modelo que utilizo ya no se siga fabricando y entonces el esfuerzo técnico para lograr otro exactamente igual será bastante mayor que si todavía se sigue vendiendo mi modelo en el mercado. Pero, en todo caso, obtener un ejemplar igual al estropeado es siempre algo factible, con más o menos dificultades técnicas. Los múltiples ejemplares del periódico del día, que son el ejemplo de repetibilidad elegido por John Crosby, ${ }^{1}$ son claramente sustituibles unos por otros. Si me confundo de periódico y leo el de mi vecino, puedo afirmar que todo sigue igual.

Muy al contrario, la intuición que guía nuestra relación cotidiana con los otros seres humanos (y también con nosotros mismos) nos dice que el hombre es irrepetible, insustituible. La muerte es quizás el hecho que nos sitúa

${ }^{1}$ J. Crosby, The Selfhood of the Human Person, p. 46. 
con más fuerza ante la irrepetibilidad humana. La pérdida de un hombre resulta siempre irreparable. Desde luego, al hombre se lo puede sustituir en ciertas funciones sociales, en algunas de sus actividades, pero no en su ser, pues no hay dos seres humanos iguales que puedan reemplazarse sin que nada se altere en el cambio. Como afirma Max Scheler, cuanto más penetramos en un hombre a través de un conocimiento guiado por el amor, más "inintercambiable, individual, único en su género, irreemplazable e insustituible" 2 nos resulta.

Dicho ya con una terminología más técnica, el problema que voy a discutir aquí es el problema de la individuación. O, mejor, el problema del individuo entendido en sentido fuerte, es decir, del individuo con "esencia individual", que no es tan sólo el ejemplar de una especie (ejemplar meramente singular, cuya singularización está dada por el "aquí y ahora"). En el ámbito no humano, la esencia de un individuo se puede repetir: el segundo periódico es copia de la esencia del primero. Pero en el caso del hombre encontramos un individuo en sentido fuerte, pues en el individuo humano lo fundamental es precisamente su individualidad, no su especie. Su individualidad no es un mero ejemplo de una especie y por esta razón posee una esencia individual que no se puede repetir en otro ejemplar de la misma especie. En pocas palabras, en el hombre sí se cumple el principio de los indiscernibles propuesto por Leibniz.

Sin embargo, la moderna ingeniería genética parece haber dado al traste con la noción intuitiva de irrepetibilidad del hombre. En la posible clonación de seres humanos ino sucede justamente que copiamos la esencia individual del hombre cuantas veces queramos? La clonación nos daría la posibilidad de repetir hombres a voluntad: miles de hombres iguales generables en cualquier momento. Del mismo modo que un ejemplar de periódico puede sustituirse por otro, un clon podría reemplazarse por otro, pues desde un punto de vista biológico son exactamente iguales. Los ejércitos de clones, que aparecen en algunas conocidas películas de ciencia ficción y que son generados artificialmente para defender a un determinado grupo de los ataques exteriores, serían ejemplos muy plásticos de hombres sustituibles.

Una objeción común contra esta posibilidad se apoya en el caso de los gemelos monocigóticos, que son clones naturales y, sin embargo, no parecen plantear ninguna dificultad filosófica. En realidad, en la clonación no habría ningún problema de repetibilidad y, por tanto, de ausencia de individuación, porque el hombre no sólo es biología, sino también cultura. Los genes influyen en él, pero no debemos olvidar la influencia del medio externo. Un clon actual de Napoleón no sería un segundo Napoleón, pues el

\footnotetext{
${ }^{2}$ M. Scheler, Wesen und Formen der Sympathie, p. 129. En todas las citas de este trabajo he modificado las traducciones castellanas cuando lo he considerado conveniente.
} 
entorno histórico en el que se desenvolvería sería muy distinto. Sin embargo, esta objeción habitual es a todas luces insuficiente. Si el hombre fuera la conjunción empírica de genes (biología) y medio externo (cultura), en realidad no sería irrepetible. Según trataré de mostrar en este trabajo, sería un ser vivo más, con más complejidad que el resto, pero esa complejidad no daría lugar a un nuevo tipo de individuación, y entonces la repetición sería posible por principio. Frente a esto, defenderé que el hombre es un individuo en sentido fuerte: el hombre es irrepetible, justamente porque es algo más que genes y medio externo.

\section{Los designadores rígidos de S. Kripke}

La filosofía clásica sospecha de la importancia del individuo como tal, es decir, como ser dotado de una esencia individual (recordemos, por ejemplo, la hacceitas de Duns Escoto); pero, sin duda, es en la filosofía contemporánea donde el problema del individuo salta al primer plano. En la filosofía analítica actual, quizás el intento más brillante para solucionar el problema de la individuación en sentido fuerte sea el de la teoría de Saul Kripke de los designadores rígidos.

Kripke critica la teoría de las descripciones definidas de Russell y Frege. Considera que para fijar el significado de los nombres propios no sirven las descripciones definidas, porque el individuo no es un conjunto de predicados. Las características de un individuo pueden variar en un mundo posible, es decir, se pueden encontrar "enunciados contrafácticos" que caracterizarían al mismo individuo. Los enunciados contrafácticos son los verdaderos en un mundo posible: en un mundo posible Moisés podría no haber sacado a su pueblo de Egipto, pero seguiría siendo Moisés.

Frente a la tesis de las descripciones definidas, Kripke sostiene que el nombre es un designador rígido, que es el mismo en todo mundo posible. Para fijarlo no valen las descripciones definidas. Se necesita un bautismo inicial por ostensión o por descripción (la descripción fija la referencia, pero no el significado como en Frege o Russell, porque se acepta que las propiedades descritas podrían cambiar); además, se necesita una cadena real de comunicación que transmita el nombre. Pero con esto todavía no hemos logrado resolver el problema filosófico de fondo. Aunque en el bautismo inicial señale el individuo y le asigne un nombre, que luego se transmite mediante una cadena real de comunicación, tengo que saber qué es lo que señalo (y qué es lo que transmito). Señalo a un individuo, que puede cambiar de propiedades en un mundo posible, pero sigue siendo el mismo. El problema entonces es saber qué hace que ese individuo siga siendo el mismo, pues sólo así conozco lo que no puede cambiar en ningún mundo posible. Desde luego, el individuo no es un conjunto de predicados (la fal- 
sedad de la teoría criticada es obvia), pero entonces hay que ofrecer otra teoría.

La propuesta más interesante que ofrece Kripke en El nombrar y la necesidad para fijar la identidad del individuo se basa en el origen; en concreto, en las células genéticas (óvulo y espermatozoide). Moisés no es la persona que sacó a su pueblo de Egipto, sino la engendrada a partir de tales células. Dice Kripke, refiriéndose a la reina Isabel II:

¿Cómo podría ser esta mismísima mujer una persona que se hubiese originado a partir de otros progenitores, de un espermatozoide y un óvulo enteramente diferentes? Podemos imaginar, dada la mujer, que varias cosas en su vida hubiesen cambiado: que se hubiese convertido en una mendiga, que su sangre real hubiese permanecido ignorada, y así sucesivamente. A uno le es dada, digamos, una historia precisa del mundo hasta cierto momento y, a partir de entonces, la historia se separa considerablemente de su curso real. Esto parece posible. Y, así, es posible que aunque hubiese nacido de estos progenitores, nunca hubiese llegado a ser reina [...]. Pero lo que es más difícil de imaginar es que hubiese nacido de padres diferentes. Me parece que cualquier cosa proveniente de un origen diferente no sería este objeto. ${ }^{3}$

¿Se puede sostener, pues, que las células genéticas proporcionan la individualidad del hombre? En mi opinión, que un individuo humano posea una individualidad irrepetible (no enunciable como un conjunto de predicados) y sea, por tanto, el mismo en todo mundo posible, no puede ser una cuestión de óvulos y espermatozoides... o, al menos, no solamente.

En efecto, la esencial unión de la mente con el cuerpo que se da en el hombre permite que el cuerpo sirva como criterio de identidad (empírico e intersubjetivo) para el individuo humano. Y entonces, a fin de fijar la identidad del hombre, podemos emplear el origen del cuerpo. ${ }^{4}$ Pero, sin duda, el problema de la identidad humana es más complejo de lo que sugiere la solución de Kripke. Aunque el cuerpo proporcione un criterio de identidad, sería erróneo suponer que proporciona la individualidad a la persona. En realidad, como veremos más adelante, la individualidad humana hay que situarla en un nivel más profundo: en lo que Scheler denomina el "espíritu", que por ser libre da lugar a los enunciados contrafácticos.

\footnotetext{
${ }^{3}$ S. Kripke, Naming and Necessity, p. 113.

${ }^{4}$ Me permito remitir a P. Fernández Beites, Fenomenología del cuerpo y bioética, donde he defendido un dualismo unitario en el problema mente-cuerpo desde el que se justifica el carácter esencial del cuerpo. Allí he mostrado que el origen del cuerpo hay que situarlo en la célula germinal; y, por tanto, de acuerdo con el dualismo unitario, en dicha célula germinal hay un proto-yo con una psique inteligente en formación. (He discutido allí también los problemas que atañen al final del cuerpo, pues sólo así es posible obtener un criterio de identidad completo.)
} 


\section{Xavier Zubiri: individualidad como singularidad y como diversidad}

En una tradición distinta de la analítica encontramos a un filósofo español cuya ontología sitúa en primer plano el tema del individuo. Me refiero a Xavier Zubiri que, en Sobre la esencia, propone una teoría en la que lo primero no es la especie, sino el individuo: "no hay individuación de la especie, sino especiación del individuo". ${ }^{5}$

En la filosofía clásica, el dato de partida es la especie y la dificultad consiste en llegar al individuo a partir de la especie. Afirmamos, por ejemplo, que hay hombres, y necesitaríamos saber qué es lo que hace que este hombre sea este hombre y no otro. Para ello empleamos el principio de individuación. Muy al contrario, Zubiri nos dice que en su teoría ontológica podemos prescindir del principio de individuación, porque en ella se parte directamente del individuo. El individuo posee una esencia individual y la búsqueda de géneros, diferencias específicas y principios de individuación se convierte en una cuestión derivada e inútil por lo que respecta al principio de individuación. En esta teoría no hay "principio" de individuación, porque no hay necesidad de él.

Efectivamente, para Zubiri el problema de la individuación se transforma en el problema de la sustantividad. Y la sustantividad es ya individual, porque su realidad sustantiva es formalmente "esta":

La realidad sustantiva no se halla compuesta de caracteres de especificación más caracteres de individuación. Por el contrario, la individualidad no es un "carácter" más, sino un "momento" primariamente constitucional: aquel momento por el que toda sustantividad es radical, determinada e irreductiblemente "esta" sustantividad. ${ }^{6}$

Así la individuación se liga a la unidad interna de la sustantividad, pues "ser 'esta' significa que la autonomía y plenitud total de la sustantividad es una unidad suficiente e irreductible". ${ }^{7}$

Si el problema de la individuación es el de la sustantividad, entonces es principalmente el problema de la esencia. El individuo es el todo sustantivo, pero al intentar ver dónde reside su individualidad, resulta inevitable

${ }^{5}$ X. Zubiri, Sobre la esencia, p. 166.

${ }^{6}$ Ibid., p. 165.

${ }^{7}$ Ibid., p. 166. En otras palabras, la individualidad es "constitución", porque, como dice Zubiri, la constitución no es otra cosa que el "modo intrínseco y propio de ser física e irreductiblemente uno" (ibid., p. 240). Así recoge Zubiri el sentido etimológico de individuo que es indiviso, no dividido: se trata de carecer de división interna, es decir, de ser "uno". Si queremos introducir la multiplicidad, diríamos que el individuo es el que está dividido del resto, el que es uno frente a muchos, es éste y no otro. Pero, incluso una vez introducida la multiplicidad, lo importante es que sea "uno", y esto depende del propio individuo, no de los otros. 
acudir a la esencia: a la esencia en sentido estricto que es la "esencia constitutiva". Ella está constituida por las notas "constitutivas", frente al resto de notas de la sustantividad, que pueden ser o "constitucionales" o "adventicias":

El "individuo" es, ciertamente, el sistema sustantivo, y sólo él; pero su "individualidad" le viene de su "momento" constitutivo. No confundamos el individuo con su individualidad misma [...] la verdadera y radical individualidad es justo la constitutiva; las demás notas, como fundadas que son, no serían individuales si no lo fueran ya las notas constitutivas. ${ }^{8}$

La individuación la proporciona la esencia constitutiva y no un principio de individuación que hubiera de añadirse a una especie previa. Y es que la tesis de Zubiri afirma que lo propiamente individual es la esencia del individuo y que por ello se puede hablar de esencia individual. La esencia es individual, no específica, porque los individuos se diferencian esencialmente. No hay esencia (específica) "hombre" y luego "este" hombre; sino esencia individual "este hombre", que es distinta de la esencia individual de este otro hombre. El individuo posee una esencia individual constitutiva, que es real, pero no es predicable (justamente por ser individual).

Podemos entrar ya a fondo en el problema de la esencia individual, y para ello hemos de empezar por señalar que existen tipos muy distintos de individualidad. En concreto, comprobaremos en este trabajo que hay tres tipos, aunque de momento me voy a referir sólo a los dos primeros, que son los estudiados por Zubiri: la individualidad como singularidad y la individualidad como diversidad (a ellos habrá que añadir la individualidad como irrepetibilidad, que es propia del hombre).

La individualidad singular, que es la única considerada en la filosofía clásica (individuo sive singulum), es unidad meramente numeral: el individuo en cuestión no es otro y ahí se agota su individualidad. Lo propio del individuo es sólo su ser "uno" frente a "muchos". Tenemos aquí la concepción clásica de Tomás de Aquino, en la que el principio de individuación se limita a singularizar. El principio de individuación es la materia signata quantitate; no la materia en general, sino esta materia. ${ }^{9}$ Podemos decir, entonces, que el individuo es el "esto de aquí" (tode ti) y que lo único que añade el individuo a la especie es la singularidad, el "aquí y ahora". Según esta teoría, la individuación no se alcanza introduciendo nuevos predicados, sino que se necesita un principio distinto, algo de naturaleza

${ }^{8}$ Ibid., pp. 212-213.

${ }^{9}$ Gallus M. Manser sostiene que, en Tomás de Aquino, el principio de individuación es la materia prima con cierta ordenación o disposición (determinación potencial), sin que pueda considerarse la cantidad como un segundo principio de individuación (cfr. La esencia del tomismo, pp. 755-782). 
no específica, no predicable. Así obtenemos la tesis de que el individuo es "inefable", pues lo que lo convierte en individuo escapa a la predicación.

En la teoría clásica, los singulares se agrupan según la misma esencia específica o especie, que es la que hace posible la predicación. La esencia específica nos lleva más allá del individuo, pues nos permite encontrar igualdades entre los individuos. ${ }^{10}$ Estas dos gotas de agua son individualmente distintas, pero tienen la misma esencia específica porque son iguales, porque ambas son "agua". Pues bien, Zubiri propone hablar en este caso no de "especie", sino de "clase". La clase está formada por individuos que son meros "singulares": son todos iguales entre sí11 y se distinguen sólo numeralmente, por ser éste y no el otro, por ser "uno" entre muchos.

¿En qué ámbito de la realidad encontramos individuos que posean solamente individualidad como singularidad? En el mundo meramente material, es decir, inanimado. Zubiri se refiere en este punto sólo a las entidades naturales, porque para él lo artificial no tiene esencia, es cosa sentido frente a cosa real; ${ }^{12}$ pero en nuestra exposición podemos añadir las cosas artificiales. Un átomo de sodio o una piedra de granito son meros singulares, y también lo son un periódico o un ordenador. Fijémonos en el átomo de sodio, que es lo que elige Zubiri como ejemplo. Un átomo de sodio posee una individualidad que es mera singularidad porque es repetible; es uno entre una multiplicidad de átomos de sodio que son todos estrictamente iguales y, por tanto, sólo se diferencia de ellos por su singularidad. Lo único propiamente individual es la singularidad, el ser éste y no otro. Todo lo demás en él, es decir, toda su esencia tiene un carácter específico, pertenece a la clase (especie), pues se repite en otros: en todos y cada uno de los átomos de sodio. ${ }^{13}$

Frente a esta noción de individualidad como singularidad, Zubiri propone hablar de individualidad en un segundo sentido más fuerte que el anterior. Se trata de la individualidad como diversidad. La diversidad se da en la "especie", pero no entendida en el sentido de la tradición (esencia específica como "clase"), sino como "especie biológica" (con lo cual la especie biológica deja de ser un mero concepto empírico, utilizado por los biólogos, y adquiere una jerarquía filosófica central). Para referirse a la "especie" así definida, Zubiri introduce el término "esencia quidditativa". Por tanto, en

\footnotetext{
${ }^{10}$ La especie sería la identidad que permite la semejanza —cuyo caso límite es la igualdad-, pero del difícil problema de los universales no puedo hablar aquí.

${ }^{11}$ La clase está en el nivel de la especie ínfima; si ascendendemos en el árbol de Porfirio la igualdad deja paso siempre a la mera semejanza.

${ }^{12}$ Como es sabido, la equiparación de cosa artificial y cosa sentido no es del todo correcta, porque la técnica actual permite construir artificialmente cosas naturales que, por tanto, son cosa real (en nuestro caso, los clones serían cosa real).

${ }^{13}$ Quizás convenga precisar que, aunque la singularidad sea el nivel inferior de la individualidad, lo cierto es que "no hay individualidad sin singularidad" (X. Zubiri, Sobre la esencia, p. 167).
} 
la teoría de la esencia de Zubiri, además de la "esencia constitutiva" (quid), tenemos la "esencia quidditativa" (quidditas). ${ }^{14}$ Y Zubiri afirma que, desde el punto de vista de la esencia física, la esencia quidditativa, si la hay, es un "momento" de la esencia constitutiva. ${ }^{15}$ La razón es que con el término "esencia quidditativa" se refiere Zubiri a la especie, pero realizada numéricamente en el individuo ("momento quidditativo individual") (en terminología aristotélica corresponde a la sustancia primera). El vocablo "esencia quidditativa" sólo se usa derivativamente para referirse a esta esencia en cuanto que es común a todos los individuos, es decir, como "unidad conceptiva" (sustancia segunda).

La esencia quidditativa hace que cada individuo pertenezca a un phylum: tenemos, pues, una generación en sentido estricto, en la que el "esquema constitutivo" del individuo se transmite a la siguiente generación. Se trata de una multiplicación física y real de las esencias individuales (y no de la mera multiplicidad de la clase). Así, la mera semejanza entre los individuos deja paso a la "similitud genérica", basada en la generación, en la multiplicación por transmisión. ${ }^{16}$

De acuerdo con esto, se entiende que en la teoría de Zubiri no suceda, como en la filosofía clásica, que la especie se contrae al individuo; muy al contrario, aquí se parte del individuo y es el individuo el que en algunos casos puede dar de sí la especie: "el individuo no es una realización individual de lo específico, sino que, por el contrario, la especie es la expansión de la esencia constitutiva individual". ${ }^{17} \mathrm{Y}$, además, esto no se produce siempre; al hablar de un individuo, "no sólo ignoro si existe o no la especie, sino que ignoro hasta si es posible su existencia en todos los casos". ${ }^{18}$

Pues bien, en el nivel de la esencia quidditativa (especie biológica), no tenemos ya la mera "individualidad singular", con singulares que son todos "iguales" (esto era lo propio de la clase), sino que ahora tenemos ya una "individualidad estricta", individuos que son necesariamente "diversos" unos de otros. "Diversidad" significa que los individuos son más que meros singulares, pues poseen una cualificación interna que impide su repetibilidad: cada individuo no es sólo "cada uno", sino "cada cual" (cada realidad es individual, pero a su modo).

En definitiva, la diversidad se produce en individuos que varían dentro de su especie. A pesar de tener algo en común, los individuos de la misma especie no se diferencian sólo por el "aquí y ahora", sino por algo más, que hace que los individuos no se repitan. Dentro de la especie se dan las variaciones individuales y no la igualdad de los individuos.

${ }^{14}$ Cfr., p.ej., ibid., p. 247.

${ }^{15}$ Ibid., pp. 222 y 225.

${ }^{16}$ Cfr. ibid., pp. 233, 244 y 310.

17 Ibid., p. 317.

${ }^{18}$ Ibid., p. 165. 


\section{El problema de distinguir la diversidad de la singularidad}

¿Dónde encontramos individuos que sean más que meros singulares, es decir, que presenten ya la individualidad como diversidad?

Tendríamos que decir que este tipo de individualidad se da en los seres vivos que poseen cierto nivel de desarrollo. Un periódico es igual al resto de los ejemplares del día, pero un perro no es igual a los perros de su misma especie (o raza o variedad). Cada perro, por ejemplo, ofrece una diversidad propiamente individual: este perro dálmata tiene algo que no tienen los otros perros dálmata. Por supuesto, no sólo el ser aquí y ahora, sino ciertas notas propias suyas que no comparte con el resto de los individuos. Como afirma J. Crosby: "Por tanto, podemos decir que el 'espacio' metafísico entre cada copia del mismo periódico es mucho más pequeño que el 'espacio' entre cada ser vivo individual de incluso la especie más elemental". ${ }^{19}$

Esta irrepetibilidad se debe a la complejidad del individuo. La esencia de los seres vivos presenta una gran complejidad de notas y por ello se produce la variedad individual. Podría hacerse una objeción inmediata alegando que la irrepetibilidad queda falsada por la existencia de gemelos monocigóticos, que son exactamente iguales. Pero no olvidemos que la complejidad del ser vivo incluye su medio ambiente. La estructura biológica del ser vivo lo convierte en un ser que se forma en contacto con su medio ambiente. En el individuo adulto hay muchas características físicas que se deben a la influencia física del medio ambiente (es el fenotipo, frente al genotipo dado innatamente) y también muchos rasgos conductuales debidos al aprendizaje producido por contacto con el medio externo. Pues bien, son justamente estas características dadas por el medio las que escapan a la repetibilidad. Aunque la repetibilidad innata se produce de modo natural en el caso de los gemelos, para que se repita el individuo total tendría que repetirse también el medio ambiente en el que vive el animal. Y si el animal está suficientemente desarrollado, esto ya no se produce naturalmente, pues la complejidad del medio va de acuerdo con la del individuo (estructura biológica y medio ambiente son nociones correlativas, es decir, a mayor complejidad biológica mayor complejidad del medio, porque el medio está formado justamente por los estímulos a los que puede responder la estructura biológica del animal).

Quizás sea necesario precisar que la diversidad de la que aquí estamos hablando se ha de dar en la especie ínfima, en la más cercana al individuo, pues si tomamos una especie superior a la ínfima, siempre hay diversidad entre los individuos: este átomo de sodio es diverso del átomo de cloro y estas dos piedras de granito son muy distintas; el periódico de ayer y el

${ }^{19}$ J. Crosby, op.cit., p. 47. Ni Crosby ni Zubiri exigen que el animal posea cierto nivel evolutivo, pero, tal como se confirmará en el resto de la sección, esto resulta claramente necesario. 
de hoy son periódicos, pero diversos. Cuando hablamos de individualidad como diversidad, exigimos que haya diversidad siempre, es decir, que la haya en la especie más cercana al individuo. Si logramos encontrar una especie (especie ínfima) en la que los individuos sean todos iguales, dichos individuos serán meros singulares (de su especie ínfima). El átomo de sodio es diverso respecto del de cloro, pero podemos localizar una especie (la de los átomos de sodio) en la que todos los ejemplares son iguales y por ello el átomo de sodio es un mero singular. Por el contrario, en el ámbito de los seres vivos con cierto nivel de desarrollo los individuos no se repiten de modo natural. Si tomo un ser vivo complejo, no encuentro otro exactamente igual a él.

Ahora bien, lo cierto es que en nuestro intento de distinguir la singularidad de la diversidad no podemos evitar tropezar de lleno con el clásico problema de la individuación. Lo diverso, lo que hace que un individuo sea distinto de otro de la misma especie, debería ser algo individual; sin embargo, ya no puede tratarse de la mera singularidad (el aquí y ahora), sino que ha de ser cierto contenido que proporciona la diversidad. Entonces no es algo "inefable". Muy al contrario, es algo que se puede predicar: este perro dálmata es más grande que este otro, tiene una mancha justamente en el ojo, tiene el pelo algo más largo... Y de este modo nos encontramos con que lo diverso del individuo se convierte en algo específico y da lugar a una especie ínfima. La especie ínfima no es la raza que permite la variedad individual, pero sí el subconjunto dentro de la misma raza formado por todos los perros dálmata iguales a éste, por los perros que tienen exactamente las características de este dálmata: este tamaño, esta mancha... Es verdad que de hecho en los seres vivos no encontramos individuos repetidos, que pertenezcan a la especie ínfima más cercana al individuo, con lo cual el subconjunto formado por los perros dálmata exactamente iguales tendría un único elemento; pero lo decisivo es que, aunque de hecho los seres vivos no se repitan, en principio se pueden repetir. Estos individuos de hecho no repetidos son en sí mismos repetibles. Entonces la diferencia entre la singularidad y la diversidad se convierte en cuestión de grados, y su frontera se vuelve difusa, sin que corresponda a la división en seres inanimados y seres vivos.

En efecto, en los seres materiales inanimados los individuos se repiten de modo natural dentro de su especie ínfima, pero sólo en los individuos más simples, como los átomos de sodio. Si los individuos materiales son algo más complejos, no átomos de sodio, sino, por ejemplo, esta piedra de granito, entonces los individuos, aunque aparentemente sean iguales, dejan de poseer una igualdad total (salvo en casos muy excepcionales) ${ }^{20}$ no logro encontrar otra piedra de granito que sea exactamente igual a ésta.

\footnotetext{
${ }^{20}$ Muy excepcionales, porque lo que exigimos es igualdad en toda la estructura interna, molecular y atómica, no sólo igualdad a simple vista.
} 
Y al considerar los seres artificiales la situación es la misma. Si éstos poseen cierta complejidad, nos damos cuenta de que la igualdad que aceptamos en un primer momento debe ser matizada: los periódicos del día no son iguales, sino que se distinguen por la nitidez de la impresión, por una mancha, por el corte de las hojas... Sólo los seres artificiales más simples, como, por ejemplo, dos pequeños trozos de plástico recién fabricados, pueden ser quizás en alguna ocasión exactamente iguales. Por tanto, podemos sostener que si los seres materiales son complejos, aparece cierta diversidad. Y esta diversidad es la que debe considerarse equivalente a la de los seres vivos menos evolucionados; también ellos parecen iguales a simple vista, pero de nuevo se distinguen entre sí, y la repetición exacta sólo se produce en casos muy excepcionales.

Mas lo importante es que la incipiente diversidad, que se da tanto en los seres materiales complejos como en los seres vivos simples, puede reducirse a la singularidad. La prueba es que los individuos se repiten naturalmente, aunque sea de modo muy excepcional. Y esta repetición puede hacerse más frecuente si utilizamos la técnica. Con una técnica muy desarrollada podemos lograr que dos trozos de plástico sean exactamente iguales. En los seres vivos menos complejos, la técnica nos permite reproducir las características innatas (por ejemplo, mediante la clonación) y copiar los ambientes. Entonces sólo nos resta lograr que en los individuos biológicamente iguales coincidan los posibles actos "espontáneos" que influyan en la propia constitución del animal; y esto sucederá si generamos un número suficiente de individuos, pues la coincidencia se producirá siguiendo las leyes probabilísticas del azar.

Pasemos ahora a los seres vivos más evolucionados, entre los que incluimos al hombre considerado como mero ser vivo. Aquí parece que encontraríamos ya una diversidad que no es reductible a la singularidad. He insinuado la razón en el párrafo anterior. La dificultad en la copia de seres vivos no se debe tanto al problema técnico de la clonación, sino a la imposibilidad de anular la influencia que tiene la espontaneidad del ser vivo en su propia constitución. El ser vivo, al contrario de las cosas inanimadas, se va formando en contacto con el medio externo y entonces su actividad espontánea desempeña un papel decisivo. Dos relojes pueden ser exactamente iguales, aunque su actividad sea diferente (que marquen horas diferentes); dos átomos de hierro son iguales, aunque sus electrones se sitúen en distintas posiciones. Pero dos seres vivos complejos que realizan distintas actividades no son iguales, pues la actividad altera la relación con el medio y esta relación tiene un carácter constitutivo para los seres vivos. Si el organismo vivo está poco evolucionado, la diferencia en la estimulación externa debida a la espontaneidad del individuo sería mínima y apenas influiría en la constitución interna de dicho individuo. Por tanto, sería posible construir un número suficiente de individuos biológicamente iguales en los que 
coincidan los actos espontáneos con influencia constitutiva. Si una ameba, por ejemplo, se dirige hacia delante cuando otra idéntica permanece quieta, la diferencia de estimulación producida parece insignificante para la constitución interna de la ameba, y en todo caso bastaría contar con un número suficiente de ejemplares para lograr que alguna ameba se dirija también hacia delante. En cambio, si el ser vivo está más evolucionado, la influencia del entorno se vuelve decisiva... y con ella pasa a desempeñar un papel fundamental la espontaneidad del individuo. Si un perro mira por los barrotes de su jaula, mientras que su gemelo juega con un hueso, esta diferencia en el comportamiento espontáneo, aparentemente tan nimia, introduce diferencias en la estructura cerebral que anulan la igualdad entre los individuos. En los seres vivos complejos hay un número tan elevado de actos espontáneos con influencia constitutiva que lograr que el orden de dichos actos se reproduzca de modo exacto quizás sea una tarea imposible empíricamente: el número de clones necesario superaría al controlable en cualquier experimento humano. Si tenemos, por ejemplo, un número muy elevado de perros clónicos en ambientes idénticos, lograremos encontrar un segundo perro que mire por la ventana cuando mira el primero; acaso también suceda que a continuación ambos coman el hueso y luego se tumben; mas acto seguido uno se sentará y el otro ladrará o volverá a mirar por la ventana.

Sea como fuera de esta cuestión, lo que aquí nos interesa es que esta irrepetibilidad como diversidad es tan sólo irrepetibilidad de hecho y no irrepetibilidad en sí. La repetibilidad sigue siendo en sí misma posible y, por tanto, la diversidad sigue siendo reductible a la singularidad. Éste es justamente el problema de la individuación. La repetibilidad es posible, porque la individuación tal como ha sido definida, como diversidad, no es suficientemente fuerte. En la individualidad como diversidad, la diferencia entre individuos se debe a la complejidad empírica de sus notas: dos individuos son distintos porque sus múltiples notas dan lugar a combinaciones muy complejas que resultan imposibles de repetir fácticamente. Pero entonces la diversidad entre individuos no es en el fondo individual, sino que vuelve a tener carácter específico (especie ínfima) o predicable, y de aquí se sigue que la repetición de individuos es en sí misma posible, aunque no lo sea fácticamente por la excesiva complejidad de las notas.

Para expresar plásticamente el significado de la "repetibilidad en sí" utilizo la teoría de X. Zubiri. Como él dice, conseguir que dos individuos diversos, no meros singulares, sean iguales es posible de potentia Dei absoluta. Por muy evolucionado que esté un animal, Dios podría crear dos animales iguales que vivan en dos mundos iguales y en los cuales coincidan los actos de espontaneidad con influencia constitutiva. Por tanto, ni siquiera en el mundo de los seres vivos más desarrollados rige el principio de los indiscernibles propuesto por Leibniz, pues los individuos siguen siendo re- 
petibles en sí mismos, aunque presenten una diversidad fáctica. Podemos decir, con Zubiri, que la irrepetibilidad no es el dato fundamental en la individuación que aquí consideramos. Si lo decisivo fuera la irrepetibilidad, ni Dios podría repetir individuos (principio de los indiscernibles), pero ha de aceptarse que Dios siempre puede repetir la misma riqueza interna en varios individuos.

En conclusión, en ningún ámbito de la realidad material considerada hasta ahora se pueden entender los individuos como irrepetibles. En los seres inanimados simples hay mera singularidad (individuos repetidos). En los seres inanimados complejos o seres vivos simples, aparece cierta diversidad, pero ésta se reduce empíricamente a repetibilidad. Por último, en los seres vivos complejos, que pertenecen al nivel de la diversidad y no de la mera singularidad, la repetibilidad de los individuos sigue siendo posible, quizás no de modo empírico, pero sí de potentia Dei absoluta.

\section{Individualidad como irrepetibilidad: M. Scheler y la esencia espiritual}

La singularidad y la diversidad se aplican a los entes distintos del hombre. Pero la tesis que voy a defender aquí, siguiendo ahora a M. Scheler y no a Zubiri, es que para el hombre hemos de introducir un nuevo sentido de individuación. El hombre no es un mero ser natural, sino que es un sujeto trascendental, que posee lo que Scheler denomina una esencia "espiritual". Y entonces en él encontramos una individualidad como irrepetibilidad, que constituye el tipo más fuerte de individuación.

Para Zubiri, la individualidad estricta no tiene que ver con la irrepetibilidad, porque considera que ésta no se da nunca: todo individuo es repetible de potencia Dei absoluta. Yo misma acabo de utilizar esta tesis zubiriana en el ámbito de los seres vivos (que incluye al hombre como mero ser vivo), pues considero que esto es correcto si nos limitamos a los individuos de los que hasta ahora hemos tratado, que son los que corresponden a lo que Edmund Husserl denominó la "actitud natural". Este ámbito es el único considerado por la filosofía clásica y en él funciona la individualidad en sentido clásico, que, en el fondo, es mera singularidad: lo individual es lo singular, el aquí y ahora, y por tanto el individuo es repetible. La mayor complejidad de su esencia puede hacer más difícil dicha repetibilidad, quizás hasta imposible de hecho, pero en sí misma es posible. La razón es que la esencia del individuo es una esencia específica y, por consiguiente, repetible.

Ahora bien, lo cierto es que fuera de lo dado en actitud natural queda todavía algo: el hombre como sujeto trascendental (y no como mero ser vivo), el hombre del que habla Max Scheler, que posee una esencia espiritual. Para él no sirve el esquema clásico, porque su esencia sólo puede caracterizarse mediante una individualidad que sea estrictamente irrepeti- 
ble. La individualidad como irrepetibilidad trascendental proporciona así un sentido más fuerte de individualidad que el de diversidad (diversidad que puede acabar reduciéndose a singularidad). De acuerdo con esto, el hombre es el único ser para el que es válido el principio de los indiscernibles: sólo el hombre posee individualidad en sentido fuerte, frente a la mera singularidad, más o menos diversa, del resto de los individuos que habitan el mundo.

No puedo dejar de indicar que Zubiri no ignora la peculiaridad del hombre, pero el problema es que, en lugar de introducir una nueva noción de individualidad, ${ }^{21}$ su propuesta es considerar que el hombre es el único ente intramundano que posee individualidad en sentido estricto (lo cual implica negar la individualidad en otros ámbitos). Para atribuir individualidad estricta sólo al hombre, Zubiri se vale del hecho de que, por ser esencia abierta, el hombre es un "ab-soluto", está "suelto", separado del mundo. Entonces el hombre no es "parte" y, por tanto, es individuo en sentido estricto (frente al resto de entes que, al formar "parte" de otros entes, no pueden considerarse auténticos individuos). Pero, en mi opinión, la opción de restringir la individualidad al hombre no acaba de ser la mejor y, además, creo que, a pesar del rechazo zubiriano a las filosofías de la conciencia, lo cierto es que el carácter ab-soluto del hombre sólo se entiende desde su condición de sujeto trascendental, de ser espiritual y no meramente empírico.

Max Scheler ha sabido insistir en la dimensión espiritual del hombre y en la importancia de la individualidad humana como irrepetibilidad. El hombre es irrepetible o insustituible (recordemos su noción clave de "solidaridad insustituible" que sólo se alcanza en la sociedad entendida como "persona colectiva", pues en la "comunidad de vida" hay mera solidaridad sustituible que no aprecia la radical individualidad personal). Veamos, pues, cómo formula Scheler su teoría de la individuación.

Para Scheler, la esencia humana es una esencia propiamente individual: irrepetible y no meramente singular. Y su tesis fuerte es que esto puede sostenerse únicamente si afirmamos que la esencia es "espiritual", pues en el plano espiritual la individuación no puede estar determinada por la materia que sólo aporta singularidad y ha de residir, por tanto, en la misma esencia.

En efecto, según Scheler, al hombre hay que atribuirle "una auténtica 'esencia'" y no solamente singularidad, como diría, por ejemplo, Tomás de Aquino. El hombre, para ser individuo en el sentido de mero singular,

${ }^{21}$ Zubiri aplica al hombre la individualidad como "diversidad". Es cierto que cuando estudia la dimensión social del hombre, propone hablar de una "individualidad diferencial" (Sobre el hombre, pp. 189-192) o de una "individualidad dimensional interpersonal" (El hombre y Dios, p. 64), que supone una individualidad "personal". Pero la individualidad personal es de nuevo la diversidad, a la que se añade el carácter abierto de la persona. 
necesita ya una esencia propiamente individual (irrepetible). La razón es que se trata de una realidad espiritual. En el terreno material (inanimado u orgánico) puede haber dos cosas distintas que tengan la misma esencia, pues su situación espacio-temporal les permite ser dos a pesar de compartir la esencia. Sin embargo, en el ámbito del espíritu sólo puede haber existencias distintas si hay esencias distintas; en este ámbito, la diferencia del ser así (Soseinsverschiednheit) es el único fundamento posible de la diferencia de existencia (Daseinsverschiedenheit).

Cuando Scheler busca un principio de individuación para la persona, lo encuentra, por consiguiente, en una esencia individual propiamente espiritual. Scheler no duda en hablar de un individuo "espiritual qua espiritual"22 y sostiene que:

la persona espiritual qua persona espiritual es en cada hombre igualmente individual en sí misma, y que el que nos la representemos menos individual, como mero ejemplar de algún universal, reside simplemente en su mayor ocultamiento debido a su modo no libre de explayarse, además de en nuestra falta de interés, en nuestra falta de amor por ella. ${ }^{23}$

Por tanto, Scheler se opone a todas las teorías que consideran que la individuación de la persona se produce gracias a factores no espirituales, como son la relación social ${ }^{24}$ y el cuerpo. ${ }^{25} \mathrm{Y}$, de acuerdo con esto, rechaza la denominada teoría "actualista", que afirma que el yo se agota en el conjunto de sus actos. La persona no puede lograr su individuación gracias al conjunto de actos que ha vivido, porque son el cuerpo y las relaciones sociales los principales factores que determinan el contenido de dicho conjunto de actos o vivencias empíricas:

Y tampoco es sólo lo que yo pienso, siento, quiero, etc., es decir, el contenido de la conciencia, lo que da por resultado la individualización del yo. Exactamente las mismas vivencias (como se presentan a una percepción interna idealmente perfecta) podrían pertenecer todavía a distintos yos individuales. Un "individuo" psíquico no es nunca el mero "conjunto" o la "suma" de sus vivencias; o una "síntesis" de ellas cuyo sujeto sólo fuese ya una así llamada actividad de conciencia "supraindividual", una "conciencia en general". ${ }^{26}$

En definitiva, para Scheler lo que individúa no es lo empírico (el conjunto de actos marcados por el cuerpo y el mundo cultural), sino la esencia

${ }^{22}$ M. Scheler, Der Formalismus in der Ethik und die materiale Wertethik, p. 501.

${ }^{23}$ M. Scheler, Wesen und Formen der Sympathie, pp. 130-131.

${ }^{24}$ Ibid., p. 131.

${ }^{25}$ Ibid., pp. 76 y 131. También Der Formalismus in der Ethik und die materiale Wertethik, p. 501.

${ }^{26}$ M. Scheler, Wesen und Formen der Sympathie, p. 237. Cfr. también, ibid., p. 76 y Der Formalismus in der Ethik und die materiale Wertethik, p. 501. 
espiritual. Esto nos permite afirmar que no hay dos individuos iguales, que cada persona es diferente de las demás. Esta "diversidad" o irrepetibilidad, que impide que haya dos individuos iguales, quizás no lo sea a simple vista, porque no se trata de un dato empírico, pero sí lo es desde luego "ante Dios":

Con esto no se ha decidido aún si la diversidad y la diversidad de valor de las personas, existente por sí misma, puede llegar a sernos dada o puede en general 'comprobarse', ni tampoco hasta qué punto es posible esto. Si no fuera posible, existiría en todo caso aquella diversidad ante la idea de Dios, que todo lo sabe y todo lo ama. Y es 'ante Dios' donde hemos de pensar como absolutamente diversas las personas y sus valores individuales, y no admitir la llamada 'igualdad de las almas ante Dios' que algunos — sin razón, según creemos— dan como doctrina del cristianismo histórico. ${ }^{27}$

\section{Ordo amoris y libertad}

El problema es precisar en qué consiste la individuación no empírica, sino espiritual. Una primera opción es recurrir a la libertad, pero veremos que Scheler intenta evitar que la libertad sea mera "libertad de indiferencia" y hace consistir entonces la individuación sobre todo en un ordo amoris. El ordo amoris es un carácter (ethos) que Scheler tiene buen cuidado de distinguir del "carácter" (Charakter) estudiado por la psicología como ciencia empírica, al que podemos denominar "carácter psicológico".

Efectivamente, Scheler reconoce en un principio la prioridad de la libertad respecto del carácter psicológico. Scheler se opone brillantemente a los intentos de determinar la individuación mediante el carácter psicológico al sostener que intentar explicar el comportamiento de un hombre a partir de su carácter psicológico y de las influencias del mundo externo es un absurdo, porque así nos quedamos "por debajo del mero sentido del problema de la libertad". Aunque conozcamos con total precisión el carácter psicológico de un hombre y las influencias del medio sobre él, ni siquiera en esta situación ideal (que es imposible de hecho) podríamos determinar el comportamiento de dicho hombre. ${ }^{28}$ Scheler apuesta, pues, por la libertad (previa al carácter psicológico), pero se encontrará con el problema de evitar que la libertad se convierta en la mera "libertad de indiferencia" de la que habla la escolástica. ${ }^{29}$

Scheler discute esta cuestión en Esencia y formas de la simpatía, poniéndola en relación con la tesis cristiana de la creación del hombre. Nuestro

\footnotetext{
${ }^{27}$ M. Scheler, Der Formalismus in der Ethik und die materiale Wertethik, p. 500.

${ }^{28}$ Ibid., pp. 476-477.

${ }^{29}$ Según Scheler, defendida por los escotistas de la Edad Media en contra de Tomás de Aquino (Zur Phänomenologie und Metaphysik der Freiheit, p. 176).
} 
autor considera que el pensamiento creacionista del cristianismo se ha deformado, pues se ha concentrado en la idea de la creación de una sustancia sin esencia originaria individuada. La sustancia humana creada por Dios carecería de una auténtica esencia individual y sólo se individuaría por la herencia, la experiencia... o por la libertad; pero el problema es que esta libertad (que no lo es de una esencia ya individual) no sería más que un liberum arbitrium indifferentae:

la desecación y el vaciamiento del pensamiento creacionista originariamente verdadero en la idea de la creación de una única "sustancia psíquica" (sin esencia originaria), indeterminada en su ser así, igual para todos los seres humanos, de una sustancia que únicamente llegaría a tener un ser así por obra de lo que la herencia y la experiencia terrestre inscriban sobre ella y lo que ella misma rinda "libremente" (en el sentido de un liberum arbitrium indifferentae). ${ }^{30}$

Para evitar que la libertad sea indiferencia, Scheler propone entender la esencia individual de la persona como un carácter (ethos) espiritual o individual (distinto del carácter psicológico), instaurado por el "ordo amoris". ${ }^{31}$

Según sostiene Scheler en su trabajo titulado Ordo Amoris, la esencia del hombre reside en su "ethos" (carácter), en su apertura sentimental a valores. El ethos de un sujeto es "el sistema, siempre articulado en cierta forma, de sus estimaciones de valor y preferencias de valor fácticas". ${ }^{32}$ La tesis de Scheler es, en efecto, que el hombre es sobre todo un ser sentimental, y no uno racional o volente. Por ello, la esencia individual del hombre hay que situarla en el terreno del ánimo (del corazón), de los sentimientos abiertos a valores. De acuerdo con esto, el núcleo del hombre es el ethos y el núcleo del ethos es el ordo amoris, que es la ordenación de los valores abiertos en el amor. Como dice Scheler en frase lapidaria: "quien posee el ordo amoris de un hombre posee al hombre. Posee respecto de este hombre como sujeto moral algo así como la fórmula cristalina para el cristal". ${ }^{33}$

El ordo amoris que nos da la esencia del hombre es individual: es la ordenación de valores que es propia sólo de este individuo, que le incumbe sólo a él. Dentro del ordo amoris hemos de diferenciar el ordo amoris en sentido descriptivo y en sentido normativo. El ordo amoris solamente de hecho o descriptivo es el empírico, el que un hombre tiene fácticamente. El normativo es el que debe tener; el que se corresponde con la escala universal, aunque, por supuesto, sólo sea una parte del universal (para

\footnotetext{
${ }^{30}$ M. Scheler, Wesen und Formen der Sympathie, p. 135.

${ }^{31}$ Cfr. por ejemplo, H. Leonardy, Liebe und Person. Max Schelers Versuch eines "phänomenologischen Personalismus", pp. 145-154.

32 Ordo Amoris, p. 347.

${ }^{33}$ Ibid.
} 
poder ser individual). Es el ordo amoris universal pero individuado, y al individuarse puede constituir la esencia del hombre.

El ordo amoris normativo es una "esencia de valor" determinada por "lo bueno-en-sí para mí", ${ }^{34}$ es decir, los valores se dirigen a mí y en esto consiste mi esencia (esencia de valor). Dice Scheler que en el contenido de lo bueno-en-sí "hay una referencia vivida a mí, una indicación vivida que parte de ese contenido y apunta a 'mí', diciendo y susurrando: 'para ti'". ${ }^{35}$ Cada persona tiene, pues, su propio deber, que la "llama" sólo a ella; y así el ordo amoris marca la "vocación" (la llamada Ruf) de cada individuo humano. El ordo amoris normativo proporciona al hombre su "puesto único dentro del cosmos moral", ${ }^{36}$ su lugar dentro del plan de salvación del mundo, su "singular faena", su " 'oficio' (Beruf) en el viejo sentido etimológico de la palabra". ${ }^{37} \mathrm{Y}$ constituye de este modo su "salvación personal". ${ }^{38}$

\section{La irrepetibilidad de la libertad}

El problema es que, en la teoría de Scheler, la esencia humana coincide finalmente con el ordo amoris, quedando en un segundo plano la otra cara de la esencia que era la libertad. ${ }^{39}$ Por mi parte, creo que hay que defender la primacía de la libertad respecto del ordo amoris: la libertad no está determinada por el carácter (ethos), sino que puede decidir sobre él. Éste es el problema de la génesis del carácter, del hacerse libre del hombre, en el que aquí no puedo entrar (la dificultad consiste en mostrar justamente que la libertad así entendida no es indiferencia). Tan sólo intentaré sugerir, frente a Scheler, que es la libertad la que en realidad proporciona la individualidad humana como irrepetibilidad.

La arriesgada tesis que aquí propongo es que la libertad ofrece la máxima individualidad porque la libertad es en sí misma irrepetible. Creo que éste es un dato último que captamos intuitivamente: al intentar determinar qué nos hace irrepetibles, se nos impone la irrepetibilidad indiscutible de nuestra libertad. Se trata de una irrepetibilidad trascendental, que es compatible con la repetibilidad empírica de todos nuestros rasgos físicos e incluso, en el caso límite, del contenido del conjunto completo de nuestros actos de conciencia. Este dato intuitivo es difícil de expresar en palabras, pero lo intentaré a pesar de todo.

Pienso en lo que me hace a mí o a cualquier otro ser humano un individuo irrepetible, es decir, un ser cuya pérdida es una pérdida absoluta,

\footnotetext{
${ }^{34}$ M. Scheler, Der Formalismus in der Ethik und die materiale Wertethik, p. 482.

${ }^{35}$ Ibid., p. 482.

${ }^{36}$ Ibid., p. 482.

37 Ordo Amoris, p. 351.

38 Op. cit., p. 481.

${ }^{39}$ Esto lo justificaré en otro lugar.
} 
que resulta irreemplazable: el hijo muerto no puede ser sustituido por un futuro hermano; el hermano es otro individuo, pero no el que ha muerto. Para explicar este dato originario, podría fijarme en mi ser biológico, en mi cuerpo. Mi complejo cuerpo, perteneciente a la especie más evolucionada que de hecho existe sobre la faz de la Tierra, parece no admitir copias. Ésta es la individualidad como diversidad de la que habla Zubiri. Pero la tesis que aquí defiendo es que si yo fuera cuerpo sería repetible. Un clon mío sería una repetición mía. Es cierto que la diversidad del ambiente resulta de hecho irrepetible y que con ella resulta irrepetible el contenido de mis actos de conciencia. Incluso aunque tú y yo seamos individuos clónicos y estemos percibiendo lo mismo ahora, yo percibo desde aquí ahora y tú desde allí ahora, y esto introduce una diferencia entre nuestros actos perceptivos. Por tanto, si queremos que coincidan empíricamente todos los actos de dos individuos, nos encontramos con algo imposible de hecho. Mas lo decisivo es que la diversidad es sólo de hecho, porque la repetición es posible de potentia Dei absoluta; es decir, Dios podría crear mundos iguales en los que hubiera dos hombres cuyas vivencias empíricas fueran exactamente iguales. Y, a pesar de todo, lo cierto es que yo no estoy repetida en un clon mío que viviera en un mundo idéntico al mío; yo no puedo ser repetida, ni siquiera por Dios. ¿Por qué?

Justamente porque soy libertad y la libertad consiste en ser "esta" libertad. Otra libertad, aunque fueran iguales sus condicionantes externos, sería absolutamente otra, nunca una repetición de la mía. Si muere un ratón, podemos pensar en un segundo ratón que sustituya al primero porque ambos son igualmente ratones, son ejemplares de una especie. Pero no podemos pensar en una segunda libertad que sustituya a la primera. La razón es que el yo libre no es ejemplar de una especie, sino que cada ser libre agota su propia "especie". Dicho de otro modo, la libertad consiste ante todo en su individualidad, en su ser "ésta", pues más allá de su ser "ésta" no queda nada de interés. En el ratón más allá de la individualidad queda el ser "ratón", y esto es lo que, sobre todo, tiene interés en él; por ello este ratón puede ser sustituido por otro, porque en el caso de los ratones lo importante es que haya un "ratón". Pero en el ser humano lo importante no es que haya un ser libre, sino que haya "este" ser libre.

La irrepetibilidad de la libertad capaz de individuar al hombre es irrepetibilidad trascendental, no empírica. Dos decisiones son distintas debido a su condición trascendental de actos libres, aunque coincidan en el contenido de la decisión tomada. Lo irrepetible son los actos en tanto que libres, no por el contenido de los mismos; por tanto, no los actos considerados empíricamente. Aunque dos individuos decidan realizar actos que tengan exactamente el mismo contenido, los actos de libertad no se repiten. Por consiguiente, hemos de dar la razón a Scheler cuando se niega a individuar a la persona mediante el conjunto de sus actos empíricos, pues 
la individuación humana queda en un plano espiritual. Pero, contra Scheler, lo que aquí defiendo es que esta individuación es sobre todo libertad (y no únicamente ordo amoris).

En definitiva, somos irrepetibles en tanto que poseemos libertad. Y la libertad consiste en hacer nuestra propia vida, en construir nuestro propio carácter individual: carácter descriptivo que ha de construirse a la luz del carácter normativo, que pone la libertad ante un mundo individual de valores. Aquí no puedo entrar en el difícil problema genético, pero al menos me gustaría mostrar su relación con el tema de la individuación.

La libertad construye nuestro carácter, que en tanto que es libre se convierte también en irrepetible. La génesis del hombre en la que se forma el carácter se lleva a cabo mediante una "libertad situada", que incorpora la "diversidad" empírica (nivel inferior de individualidad) a la pura libertad trascendental. Por ello, una vez gestado el carácter, su diversidad empírica se convierte en irrepetibilidad: el hecho de haber sacado a su pueblo de Egipto llega a formar parte de la esencia irrepetible de Moisés. Y así volvemos al problema planteado por Kripke de los enunciados contrafácticos. Convertir la libertad en esencial para el hombre exige introducir una nueva noción de necesidad según la cual es "necesario" que Moisés haya sacado a su pueblo de Egipto (pues, una vez realizado, esto pertenece a su esencia fáctica irrepetible), pero es necesidad por libertad, porque Moisés podría no haberlo hecho (enunciados contrafácticos). Veamos esto para terminar.

El hombre se hace libremente y podemos decir con Zubiri que, aunque es siempre "el mismo" (esencia constitutiva), no es siempre "lo mismo" (esencia constitucional). Lo que el hombre va haciendo de sí mismo es esencial, porque es el resultado de su libertad, y a esto es a lo que Zubiri denomina la "esencia constitucional", frente a la "esencia constitutiva" (correspondiente a la esencia clásica invariable). En mi esencia no puedo prescindir del resultado de la libertad, pues soy esto que he hecho de mí (esencia constitucional).

La libertad implica que los contenidos de la esencia humana (constitucional) no son necesarios ni siquiera en estas circunstancias. En estas circunstancias yo he hecho esto, pero ser libre significa precisamente que podría no haberlo hecho: Moisés podría no haber sacado a su pueblo de Egipto. En estas circunstancias podría no ser como soy y, sin embargo, seguiría siendo yo. Por eso soy libre, porque decido lo que soy. De este modo comprobamos que, efectivamente, las notas de las descripciones definidas de Russell y Frege no pueden determinar la esencia, porque la libertad (esencia constitutiva) hace que las notas empíricas que caracterizan al hombre pierdan su carácter necesario: soy así, poseo estas notas empíricas concretas, pero, por ser libre, podría haber sido de otro modo, podría poseer unas notas muy distintas. Los mundos posibles de los enunciados contrafácticos son, pues, sobre todo, los mundos que abre la libertad. 
Pero entonces tenemos que cambiar la noción de necesidad. La necesidad ya no puede significar permanencia de notas o predeterminación en el cambio de las notas. Las notas por libertad (notas constitucionales) son necesarias en este nuevo sentido tan sólo en cuanto que pertenecen a la esencia: dependen de la esencia (constitutiva) y forman la esencia (constitucional). Por ello eliminarlas sería eliminar la esencia. La necesidad no significa que las notas constitucionales tengan que haber sido éstas, sino que podrían haber sido otras, pero una vez que son éstas ya no puedo eliminarlas y se convierten en necesarias, pues constituyen mi esencia (es decir, no me resultan accidentales). En otras palabras, el acto de libertad decide qué es lo necesario, en el sentido de lo esencial (constitucional). Lo necesario podría haber tenido otro contenido, pero tiene éste porque así lo ha decidido la libertad.

Ciertamente nos encontramos aquí con una situación paradójica: lo que ahora soy me resulta esencial, es necesario que sea ahora este ser concreto que soy, pero afirmo que soy libre porque mi ser concreto podría haber sido otro. Intentemos hacernos cargo hasta el final de esta paradoja decisiva. Si ahora poseo la nota $A$, la libertad significa que esta nota podría haber sido $B$. Pero lo que sostenemos al defender la esencialidad de la nota $A$ es que una vez que es $A$, no puede ser $B$ (aunque podría haber sido $B$ ). Si ahora es $A$, ahora no puedo sustituir $A$ por $B$, ya que al hacerlo destruiría mi esencia y la transformaría en algo distinto. Es decir, el resultado de la libertad podría haber sido otro, pero una vez que es éste, se convierte en esencial. Por ello acostumbramos a decir que a Moisés le es esencial haber sacado a su pueblo de Egipto, porque al hablar acerca de cualquier persona nos situamos ya en un momento posterior a la realización de sus actos libres, y entonces los resultados concretos de dichos actos ya le resultan esenciales (constitucionales). Si en la esencia "Moisés" ya realizada eliminamos el hecho de haber sacado libremente a su pueblo de Egipto, destruimos la esencia y obtenemos otro individuo (pero esto no obsta para que Moisés pudiera no haber sacado a su pueblo de Egipto y haber seguido siendo Moisés).

En definitiva, la paradoja surge por tomarse en serio la libertad. Es importante que mi esencia concreta sea ésta y no otra, precisamente porque podría haber sido otra. El resultado de mi libertad es importante en cuanto que es concreto, pues es lo que he hecho de mí, pero su importancia reside en lo que tiene de no concreto, de libertad, es decir, en el hecho de que su concreción podría ser otra muy distinta (enunciados contrafácticos).

Podemos ya concluir. Lo que he intentado mostrar en este trabajo es que si entendemos al hombre como un sujeto trascendental libre, entonces podemos afirmar que entre dos individuos humanos hay siempre y necesariamente una desigualdad trascendental. El hombre es así un individuo en sentido fuerte: posee una esencia individual, que es irrepetible. Irrepe- 
tible, porque ni siquiera Dios puede repetir un individuo humano. Repetir un hombre significaría repetir sus actos libres, pero esto sería justamente anular su libertad y, por tanto, su misma condición humana.

\section{BIBLIOGRAFÍA}

Crosby, John, The Selfhood of the Human Person, The Catholic University of America Press, Washington, 1996.

Fernández Beites, Pilar, Fenomenología del cuerpo y bioética, Ed. Cristiandad, Madrid, en prensa.

Kripke, Saul, Naming and Necessity, Basil Blackwell, Oxford, 1990. [Versión en castellano: El nombrar y la necesidad, trad. Margarita M. Valdés, Instituto de Investigaciones Filosóficas-UNAM, México, 1985.]

Leonardy, Heinz, Liebe und Person. Max Schelers Versuch eines "phänomenologischen Personalismus", Martinus Nijhoff, La Haya, 1976.

Manser, Gallus M., La esencia del tomismo, 2a. ed. corr. y aum., de acuerdo con la 3a. ed. alemana, Instituto Luis Vives de Filosofía, Madrid, 1953.

Scheler, Max, Der Formalismus in der Ethik und die materiale Wertethik, en Gesammelte Werke, vol. 2, sechste, durchgesehene Auflage, Francke, Berna/Munich, 1980. [Versión en castellano: Ética, trad. Hilario Rodríguez Sanz, ed. Juan Miguel Palacios, Caparrós, Madrid, 2001.]

—- Wesen und Formen der Sympathie, en Gesammelte Werke, vol. 7, durchgesehene Auflage von "Phänomenologie und Theorie der Sympathiegefühle", Francke Verlag, Berna/Munich, 1973. [Versión en castellano: Esencia y formas de la simpatía, trad. José Gaos, Losada, Buenos Aires, 1943.]

_- Zur Phänomenologie und Metaphysik der Freiheit, en Schriften aus dem Nachlaß, Band I, en Gesammelte Werke, vol. 10, Bouvier, Bonn, dritte, duchgesehene Auflage, 1986, pp. 155-177.

—- Ordo Amoris, en Schriften aus dem Nachlaß, Band I, en Gesammelte Werke, vol. 10, pp. 345-376. [Versión en castellano: Ordo amoris, trad. Xavier Zubiri, Caparrós, Madrid, 1996.]

Zubiri, Xavier, Sobre la esencia, Alianza, Madrid, 1985.

—, El hombre y Dios, 2a. ed., Alianza, Madrid, 1985.

— Sobre el hombre, Alianza, Madrid, 1986.

Recibido el 2 de junio de 2004, aceptado el 1 de febrero de 2005. 